\title{
Parental transmission and the importance of the (non-causal) effects of education on political engagement: Missing the forest for the trees
}

\author{
Stig Hebbelstrup Rye Rasmussen ${ }^{1}$ And Aaron Weinschenk ${ }^{2}$ A N D Christopher T. Dawes ${ }^{3}$ \\ AND Jacob v.B. Hjelmborg ${ }^{4}$ A ND Robert Klemmensen ${ }^{4}$ \\ ${ }^{1}$ University of Aarhus \\ ${ }^{2}$ University of Wisconsin-Green Bay \\ ${ }^{3}$ New York University \\ ${ }^{4}$ University of Southern Denmark
}

\begin{abstract}
By most accounts, an important prerequisite for a well-functioning democracy is engaged citizens. A very prominent explanation of variation in political engagement suggests that parental transmission through socialization accounts for individual-level differences in political engagement. In this paper, we show that classic formulations of parental transmission theory can be supplemented by findings from the bio-politics literature, allowing us to disentangle when heritable factors are important and when socialization factors are important predictors of political engagement. The paper demonstrates that the effect of education on various measures of political engagement is confounded by both genes and parental socialization; no previous study has documented the importance of both of these confounders. We then go on to show that as the level of family politicization and consistency increases, the influence of genes decreases. We take this to imply that family socialization can compensate for (genetic) individual differences and foster increased political engagement. By only focusing on the "causal" effect of education, we are missing the forest for the trees.
\end{abstract}

\section{INTRODUCTION}

For a democratic society to thrive, it is essential that the citizenry is politically interested, knowledgeable, and involved in the democratic process. Consequently, substantial effort has been devoted to trying to understand how we cultivate engaged citizens. A dominant explanation has been that parents, through the socialization of their offspring, can affect levels of political engagement among the next generation. A second important explanation emphasizes that (civic) education enhances the propensity of citizens to be interested and involved in politics. This idea was perhaps most clearly articulated in Philip Converse's famous statement that education is the "universal solvent" (Converse 1972).

However, a series of studies have questioned these claims and have argued that the causal effect of education on political engagement is either exaggerated or, in some cases, even nonexistent. According to these studies, education is a proxy for the influence of family upbringing and/or genetic dispositions (e.g., in the form of personality traits and cognitive abilities) (Berinsky and Lenz 2011; Highton 2009; Kam and Palmer 2008). So far, most of the literature has been somewhat one-sided, arguing either that there is a causal effect of education or there isn't. Very few studies have actually tested some of the proposed confounders suggested in the literature so far, although two notable exceptions are studies by Rasmussen (2015a) and Oskarsson et al. (2017). Rasmussen (2015a) shows that the effect of education on political knowledge is (partially) 
confounded by personality traits and cognitive ability, and Oskarsson et al. (2017) demonstrate that the effect of education on social trust is completely genetically confounded.

It is surprising that these two quite distinct literatures have not cross-fertilized much, since both stand to gain by learning from the theoretical and empirical insights of the other. What if we are missing the forest for the trees? What if there is an important influence of education on political engagement, but one that is not well captured by only focusing on estimating the causal effect of education, or by focusing exclusively on (genetic) confounding? This article remedies some of these shortcomings by combining insights from both lines of research to study the (non-causal) effects of education on political engagement and the important conditioning effects of the family environment.

From the classic literature on parental transmission of (political) values, attitudes, and behaviors (Hyman 1959; Jennings and Niemi 1968), it should come as no surprise that part of the variation in (the effect of education on) political engagement is explained by parental influences. Indeed, we would expect this to be the case, especially when the conditions for transmission are ideal, such as in the case of family politicization (Jennings, Stoker, and Bowers 2009). But what happens when conditions are not ideal? By combining these perspectives, we make three contributions to the literature.

First, the classic literature on familial transmission has paid little attention to the fact that (part of) the familial transmission might take place through genetic transmission. This is not because the literature is unaware of this potential mechanism, but instead because there has been a lack of suitable data sources. This fact is clear from the work of Jennings, Stoker, and Bowers (2009), who, when writing about parental transmission of values, note that "... it is possible that genetic mechanisms are doing at least some of the work. It remains for additional research to reconcile and perhaps integrate these two approaches to understanding parent-child concordance" (796). By drawing on insights from the bio-politics literature, which has stressed the importance of genetic inheritance (Alford, Funk, and Hibbing 2005; Fowler, Baker, and Dawes 2008; Dinesen et al. 2016; Oskarsson et al. 2017), we can develop a better understanding of when and why familial transmission, as opposed to genetic transmission, matters for the effect of education on political engagement.

Secondly, the literature on the causal effect of education on political engagement has paid little attention to the fact that it is not only genetic dispositions that might confound the effect of education. Family upbringing likely also plays an important role. Although Kam and Palmer (2008) highlighted the importance of family upbringing as a potential confounder of the effect of education on political engagement, few studies, to our knowledge, have actually been able to demonstrate empirically the importance of this potential confounder for political participation. ${ }^{1}$

Thirdly, and related to the above point, the studies on the causal status of education on political engagement have been quite static and empirical in nature. Studies have largely focused on whether there is a causal effect of education or not. The literature on family transmission provides a much more detailed and nuanced theoretical understanding of when and why family transmission is important. As discussed in more detail below, this literature draws on social learning theory to derive clear hypotheses about when the impact of family transmission should set in and when it should not. Family politicization and family stability have been shown to be important moderators in the transmission of political attitudes from parent to child (Jennings, Stoker, and Bowers 2009). Specifically, this literature argues that the effect of parental influence (through socialization on political engagement) could either increase the effect of education on political engagement (i.e., a Matthew effect - "the rich get richer and the poor get poorer") or

${ }^{1}$ A partial exception is the study by Robinson (2020) on education and political knowledge. 
compensate for those who lack an education (i.e., a compensation effect) (Damian et al. 2015; Neundorf, Niemi, and Smets 2016).

These different effects have very different implications for our understanding of the role of education in fostering democratic citizenship. Scholars like Nie, Junn, and Stehlik-Barry (1996) have argued that one of the most important predictors of politically engaged citizens is education. If education merely serves as a vessel for parental differences in education, this would call into question the role that education plays in creating democratically engaged citizens. On a deeper level, such a finding would also call into question the ability of education to act as a social leveler and thus its ability to lift citizens above and beyond the social environment they are born into.

\section{EDUCATION AND POLITICAL ENGAGEMENT}

Education has traditionally been seen as a great force for leveling differences in political participation and political engagement and as a vehicle for enhancing political equality (Converse 1972; Nie, Junn, and Stehlik-Barry 1996). This effect of education has been questioned most notably in the thought-provoking paper by Kam and Palmer (2008). Later research finds mixed results with regard to the causal relationship between education and political participation. For example, Henderson and Chatfield (2011), Mayer (2011), and Sondheimer and Green (2010) find that education is causally related to political engagement, while Kam and Palmer (2011), Berinsky and Lenz (2011), and Persson (2014) find very little or no effect of education on political engagement. ${ }^{2}$

Several interesting insights have emerged from this debate. First, it might be less interesting to study the effect of education and more interesting to focus our attention on what education actually affects. For instance, Rasmussen and Nørgaard (2018) found that there is an effect of education on (political) resources, while there is no effect of education on cognitive and motivational factors related to political tolerance. Somewhat similar findings of moderate to strong levels of confounding of education on cognitive and motivational factors have been reported by Rasmussen (2015b, 2016).

The second insight is that the effect of education is likely contextual. For instance, Campbell (2009) shows that the effect of education on participation depends on the competitive environment in which a person is situated. If one's peers are also highly educated, education has a smaller effect on political participation, compared to contexts where they are surrounded by citizens who hold less formal education. Similar findings have been reported for internal efficacy (Rasmussen and Nørgaard 2018). Recently, two studies have focused on the effect of parental socialization on education. Robinson (2020) found that while the effect of education on political knowledge is completely confounded by pre-adult factors, there is indeed an effect of education on political knowledge in families who discuss politics frequently. Similarly, Lindgren, Oskarsson, and Persson (2019) find no effect of education on political participation but show that in families with low SES, raising levels of education can compensate for pre-adult proclivities to participate. Finally, Oskarsson et al. (2020) find, using a novel adoptee design, that exposure to consistent parental behavior weakens the influence of genetic predispositions on turnout.

Building on these insights, we argue that by focusing on whether or not there is $a$ causal effect of education, we are possibly missing the forest for the trees; there is a lot going on beneath the

${ }^{2}$ Some studies have found that the effect of education on participation is substantially reduced after accounting for confounders rooted in the family but that an effect still remains in some contexts (Burden et al. 2020; Gidengil et al. 2019; Dinesen et al. 2016). For a detailed overview of the literature on education and participation, see Persson (2015). 
surface that is also highly important in terms of education helping to achieve political equality. Our goal is to advance this literature in two ways by drawing on behavioral genetics. First, we investigate whether the effect of education on political engagement is confounded by family upbringing and/or by genetic differences. The answer to this question has very important potential policy implications. Indeed, if the effect is confounded by family upbringing, it could suggest that changing family SES would make a difference in shaping political engagement and that political equality is possible (Lindgren, Oskarsson, and Persson 2019).

In this paper, we examine a range of political outcomes that capture psychological and behavioral engagement in politics. More specifically, we focus on political participation, political interest, consumption of political news, and external political efficacy. Investigating multiple aspects of political engagement allows us to conduct a fairly thorough investigation of the effect of education on political engagement, an important democratic construct. ${ }^{3}$

Secondly, and perhaps more importantly, we disentangle the moderating influence of the rearing environment. Robinson (2020) finds that the within-twin effect of education on political knowledge is moderated by the level of family discussion of politics. Thus, although the main effect of education on political knowledge is not significant, for those families that discuss politics frequently, the effect of education is indeed significant. Robinson (2020) uses a fixed-effect model on identical twin pairs, which means that it is impossible to investigate whether the confounding influence of genetics and the rearing environment depends on the level of the moderator (in this case whether the effect of genes or rearing environment is different for high- and low-SES families). ${ }^{4}$ Johnson et al. (2010) argue this could be due to the differences in educational systems: universal access to education vs. a more selective educational system in the United States. Exactly how this moderation is expected to take place is elaborated below.

\section{Political SOCIALIZATION}

Social learning theory (Bandura 1969, 1986) has been used to explain the correspondence between parent-child political attitudes such as party identification and interest in politics (Jennings, Stoker, and Bowers 2009). The more frequent and salient the cues are, the more likely the transmission through social learning. In the context of political life, this would imply that the more politicized the family is, the stronger the transmission (Jennings, Stoker, and Bowers 2009). This expectation forms the basis of our first hypothesis:

- Hypothesis 1: The more politicized the family rearing environment, the stronger the moderation of the effect of education on political participation.

The second theoretical lesson from the literature on social learning and political transmission of values from parent to child is the important role of consistency. The more consistent the transmission of cues (Jennings, Stoker, and Bowers 2009), the more likely there is to be transmission. In the context of political attitudes, we know that people with higher levels of education also have more coherent and stable attitudes (Delli Carpini and Keeter 1996). This forms the basis of our second expectation:

${ }^{3}$ There is some debate about whether external efficacy should be related to political engagement. Nie, Junn, and Stehlik-Barry (1996) argue that political efficacy belongs to their political enlightenment dimension whereas Verba, Schlozman, and Brady (1995) argue that it does not.

${ }^{4}$ Johnson et al. (2010) find that for those with high scores on a cognitive ability test, shared environmental influences were important for explaining educational attainment in Sweden, whereas in Minnesota shared environmental influences were particularly important for those with low scores on cognitive ability. 
- Hypothesis 2: The higher the level of education in the rearing environment, the stronger the moderation of the effect of education on political participation.

\section{METHODS AND DATA}

\section{Data and case}

Participants were drawn from the Danish Twin Registry's younger cohort of twins born in the years 1970-1989. The twins were surveyed three times. We use data from the first wave, which was collected in 2009. The only exception is for our measure of politicization, which is only available in the second wave. All analyses using the measure of politicization thus have a smaller sample size compared to the rest of the analyses. The Danish Twin Registry is very similar to the general population in terms of educational attainment and political attitudes (Christensen et al. 2006; Klemmensen et al. 2012).

\section{Measures}

Descriptive statistics for all measures can be found in Appendix 11.

Political participation. Participation is measured by four items asking about a series of political and social activities such as "Signed a petition" and "Participated in a demonstration." The full set of activities can be found in Appendix 2. The answer categories are as follows: "Have done within the last year," "Have done it at an earlier time," "Have not done it but might do it," "Have not done it and will never do it" (as well as a "Don't know" option). The measure of political participation is a summative index of the individual items. Alpha reliability is 0.64 for this index.

Political interest. Political interest is measured by asking respondents "How interested are you in politics?" on a four-point scale ("Very," "Somewhat," "Not very," or "Not at all" interested).

External efficacy. External efficacy is measured using two questions on the responsiveness of government. The questions are translated from the well-known ANES "NOSAY" and "NOCARE" items (Niemi, Craig, and Mattei 1991). The first asks whether respondents agree with the statements "People like me have don't have any say about what government does" and "I don't think the government cares much what people like me think." The answer categories were "Completely agree," "Agree," "Partially disagree," and "Completely disagree" (as well as a "Don’t know" option). Our measure of external efficacy is a simple summative score of these two items; alpha reliability is 0.80 for this score.

Consumption of political news. Consumption of political news is measured using the question "How often do you follow politics either via TV, radio, or by reading newspapers?" Respondents could answer with "Every day," "Multiple times a week," "One or two times a week," "Rarely," or "Never."

Consistency. We measure family consistency using a question about the main provider's level of education, which ranges from "No vocational education" to "Long-term higher education." The full range of categories can be found in Appendix 2. 
Family politicization. Family politicization is measured using the question "Growing up, how often did you discuss politics with your family (except your twin)?" The answer categories were "Never," "Rarely," "Now and then," and "Often."

Demographics. Age and gender are ascertained from Danish registries.

\section{Methods}

Discordant twins and the causal effect of education on political participation. Twins have recently been used quite a few times in political science as a "natural experiment," and many studies have focused on MZ (i.e. "identical") twins when examining the relationship between education and political attitudes and behaviors (Dinesen et al. 2016; Oskarsson et al. 2017; Robinson 2020; Weinschenk and Dawes 2019; Weinschenk, Dawes, and Oskarsson 2020). The idea is quite simple: Since MZ twins reared together share both their upbringing and segregating genes, they are matched on many likely confounders when investigating the causal effect of education on political behaviors and attitudes. If one twin has a higher level of education, we can investigate whether this within-twin pair difference also leads to higher levels of participation for the twin with the higher level of education compared to the twin with a lower level of education. This model is typically referred to as a "twin-pair fixed-effects" model.

Although this model is ideally suited for using twins to draw (quasi)-causal inferences (Turkheimer and Harden 2014; McGue, Osler, and Christensen 2010), it is less ideal if we also want to investigate the extent to which we observe genetic confounding or confounding by the (social) rearing environment. Since we are only investigating the within-twin pair differences when using a fixed effects model, we are throwing away important information in the process. To understand this, we need to be a bit formal. The variance of any trait can, according to standard biometrical modeling (Neale and Cardon 2013), be decomposed into three components: an additive genetic component (A), a common environmental component (C), and non-shared factors (E). The total variance can thus be written as follows, where the subscript refers to the first and second twin in a twin pair:

$$
\operatorname{cov}\left(T_{1}, T_{2}\right)=a^{2}+c^{2}+e^{2}
$$

These parameters refer to the proportion of variance attributable to additive genetic influences, shared environmental influences, and non-shared environmental influences. Shared or common environmental influences (C) are those which the twins share equally, such as family SES or parenting style, whereas non-shared environment refers to those factors that are unique to each twin such as differences in parenting style or differences in friends (Plomin and Daniels 1987).

Using twins allows us, in a direct and intuitive way, to estimate these parameters by taking advantage of the fact that MZ twins share 100 percent of their segregating genes whereas dizygotic (fraternal) twins share, on average, half of their genes. We can therefore write the covariance for these two groups as follows:

$$
\begin{aligned}
& \operatorname{cov}_{M Z}=a^{2}+c^{2} \\
& \operatorname{cov}_{D Z}=\frac{1}{2} a^{2}+c^{2}
\end{aligned}
$$


Using this information, we can calculate the heritability using Falconer's formula (Falconer 1996) by subtracting two times the differences between the correlation obtained from MZ twins compared to DZ twins. $^{5}$

What we are interested in in this paper, however, is not the estimation of heritability but the quasi-causal effect of education on political participation. In order to estimate this, in a sense we need to estimate two ACE models using a so-called Cholesky decomposition (Neale and Cardon 2013), as illustrated in Figure 1 below.

Figure 1: Cholesky decomposition

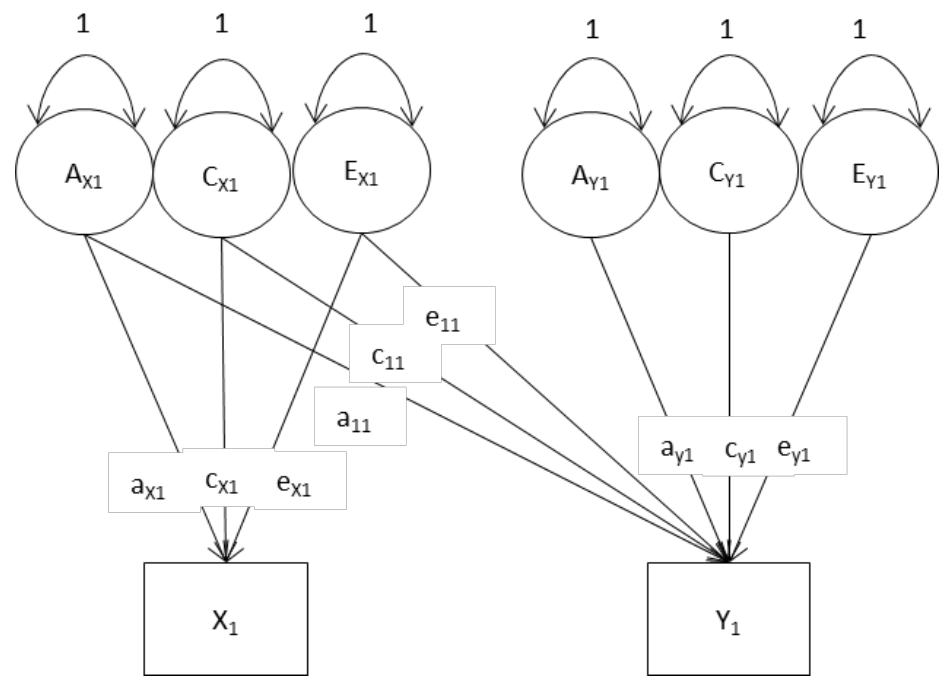

An easy way to understand the model is by drawing an analogy to OLS regression. Each of the variance components for the first variable $\mathrm{X}\left(A_{x 1}, C_{x 1}\right.$, and $\left.E_{x 1}\right)$ can be thought of as separate quantities which are regressed on the second variable $\mathrm{Y}$. The variance components for the second variable $\left(A_{y 1}, C_{y 1}\right.$ and $\left.E_{y 1}\right)$ are simply an ACE model estimated on the residual variance (i.e., after the shared variance is taken into account). The shared paths (paths $a_{11}, c_{11}$, and $e_{11}$ ) are thus nothing more than regression coefficients, each representing different quantities. If we know the variance of $\mathrm{A}$ and the covariance between this parameter and $\mathrm{Y}$, we can calculate the effect as we would in ordinary OLS (i.e., $\frac{\operatorname{Cov}(X, Y)}{\operatorname{Var} Y}$, which translates into $a_{11}=\frac{\operatorname{Cov}\left(A_{X}, Y\right)}{\operatorname{Var}_{A}}$ for the effect of additive genetics from $\mathrm{X}$ on $\mathrm{Y}$ ).

It turns out that the parameter $e_{11}$ corresponds to what we would obtain if we had simply used a fixed effect model. We outline this in more formal detail in Appendix 3, but it is quite easy to understand this on an intuitive level. Again, using an OLS analogy can help with the understanding. Since we are "controlling for" both the additive genetic effects $\left(a_{11}\right)$ and the effects of the rearing environment $\left(c_{11}\right)$, what is left is exactly the within-twin pair differences in a pair (i.e., whether the twin who has a higher level of education is also more participatory).

If we only use a fixed effect model, though, we would be unable to investigate whether genetic confounding or confounding by the rearing environment is the reason why the effect of education

${ }^{5}$ For instance, if the within-twin correlation between two traits is .4 for MZ twins and .2 for DZ twins, the estimated heritability would be $2(0.4-0.2)=0.4$ 
on political participation is either a proxy or at least overestimated. And, more importantly, we would be missing the opportunity to investigate how these change as a function of family stability and/or family politicization. As we will demonstrate below, there is no quasi-causal effect of education on political participation, but the effect of genetic confounding decreases as the level of family stability and politicization increases. By not allowing our model to investigate the (non-causal) effect of education on participation, we would be missing the forest for the trees. To allow these parameters to vary as a function of family stability and politicization, we need to elaborate slightly on Figure 1 and estimate a so-called gene-environment interaction model.

The moderating effect of family stability and politicization. The Cholesky decomposition allows us to investigate whether the parameters $a_{11}, c_{11}$ or $e_{11}$ are moderated by family politicization or stability. Before discussing the model more formally, is it worth reiterating the substantive interpretation of the moderation parameters. Robinson (2020) demonstrates that the quasi-causal effect of education (i.e., path $e_{11}$ ) on political knowledge decreases as the level of discussion in the home growing up increases. But what would be the implication of the moderation of the paths $a_{11}$ and $c_{11}$ ? If we find that the effect of $a_{11}$ decreases (and $c_{11}$ or $e_{11}$ are not moderated) as a function of family stability, this would imply that genetic differences are (relatively) less important for the effect of education on participation if you grow up in a family environment characterized by stability. Substantively speaking, this would suggest that we can increase (the effect of education on) political participation by changing the level of family SES. In short, high SES within families may be able to compensate for the genetic effect of (education on) political participation. Conversely, if genetic confounding increases as the level of family stability increases, this would indicate the existence of a Matthew effect. With this short substantive digression, we will briefly outline the moderation model in more formal detail.

The moderation in our model is very similar to a classical OLS moderation effect (Brambor, Clark, and Golder 2006; Hebbelstrup Rye Rasmussen et al. 2021) and can be interpreted as such. For instance, if we have an independent variable (e.g., education) and a dependent variable (e.g., political participation) and family stability is the moderator (M), we would estimate it as follows using OLS:

$$
Y=\beta_{0}+\beta_{1} X+\beta_{2} Z+\beta_{3} X M+\epsilon
$$

Here we can assess whether the interaction effect is significant by a significance test for the parameter $\beta_{3}$ and we can plot the effect at interesting levels of the moderator (e.g., from high to low by calculating the marginal effect-taking the partial derivative of $\mathrm{Y}$ with respect to $\mathrm{X}$ ):

$$
\frac{\partial Y}{\partial X}=\beta_{1}+\beta_{3} M
$$

This is completely analogous to the situation for the gene-environment interaction model we are using here (Purcell 2002). We do this by letting the covariance vary as a function of our moderator. Thus, we can calculate the moderation effect for path $a_{11}$ as:

$$
\frac{\partial A}{\partial Y}=a_{11}+\beta_{M_{a}} M
$$

Some care is needed in terms of drawing causal inferences for the moderating effect of family consistency and family politicization. Obviously these are not randomly assigned and at the same 
time are highly correlated with offspring education. For example, we know from previous studies that genes associated with educational attainment are also associated with social mobility and inequality (Belsky et al. 2018; McGue et al. 2020; Barth, Papageorge, and Thom 2020, 2020). We encourage future studies to investigate the robustness of the results presented here.

\section{Model estimation}

All models were estimated in Mplus version 8 (Muthén and Muthén 2017) using the MplusAutomation (Hallquist and Wiley 2018) package in $\mathrm{R}$ and all plots were created using ggplot2 (Wickham 2016). We present bootstrapped standard errors using 1000 repetitions since standard errors for parameters nearing their boundary are not normally distributed. ${ }^{6}$ All models include age and gender as controls, as is standard for biometrical modeling (McGue and Bouchard 1984). Missing data is handled using full information maximum likelihood (Enders 2010), which is the Mplus default. All variables have been rescaled to range between zero and one.

For the Cholesky models, we ran a series of models to investigate whether we could reduce the model without significantly reducing the fit of the model. We therefore first estimated a full Cholesky model (i.e., with all the parameters in Figure 1). We then ran models where we constrained one or more parameters to zero. We then chose the model with the lowest AIC that did not lead to a statistically significant reduction in model fit (Neale and Cardon 2013). If an A, C, or E model parameter is not significant, we do not investigate its cross path (i.e. paths $a_{11}, c_{11}, e_{11}$, since it does not make much sense to investigate the covariance of a construct without any significant variance). These results are presented in Tables 3-5 in Appendix 1.

For the moderation models, we only estimated interaction effects for the cross paths that were significant in the final model-fitting process. This also the typical practice in OLS unless we are dealing with a cross-over interaction, which we are not theorizing here (Loftus 1978).

The treEs: THE NON-CAUSAL EFFECT OF EDUCATION ON POLITICAL ENGAgEMENT

The results for the effect of education on our measures of political engagement can be found in Table 1 below. In none of the cases is the quasi-causal effect of education on any of the measures of political engagement significant. If we were thus only interested in the (quasi-causal) effect of education on political engagement, the story would end here. Since we have estimated a Cholesky model, however, we can also see that in all cases, this is caused by genetic confounding. The reason we see an association between education and political engagement is because genetic differences which give rise to political engagement also give rise to differences in education (i.e., common cause confounding).

It is also interesting to note what the results do not show: We find no evidence of confounding by the shared environment (C). Although we find a significant $\mathrm{C}$ component for both education on the one hand and political participation and political interest on the other, in no case is the effect of education on political engagement confounded by this component. This finding is particularly interesting from the perspective of the classical socialization literature on the parental transmission of political attitudes and behaviors (Jennings and Niemi 1968). Although this literature has itself highlighted the potential for genetic influences on the transmission of attitudes and behaviors (Hyman 1959), this is, to our knowledge, the first study to actually demonstrate that only genetic influences matter for a wide range of measures of political engagement.

${ }^{6}$ https://www.statmodel.com/examples/genetics.shtml 
TABLE 1: Cholesky decomposition for the effect of education on measure of political engagement

\begin{tabular}{ccccc}
\hline Parameter & Political interest & Consumption of news & Participation & External efficacy \\
\hline \multirow{2}{*}{ a1 } & 0.682 & 0.708 & 0.675 & 0.699 \\
& {$[0.532 ; 0.832]^{*}$} & {$[0.565 ; 0.851]^{*}$} & {$[0.528 ; 0.822]^{*}$} & {$[0.545 ; 0.852]^{*}$} \\
c1 & 0.413 & 0.368 & 0.424 & 0.387 \\
& {$[0.146 ; 0.679]^{*}$} & {$[0.043 ; 0.693]^{*}$} & {$[0.198 ; 0.651]^{*}$} & {$[0.100 ; 0.674]^{*}$} \\
e1 & 0.555 & 0.555 & 0.556 & 0.554 \\
& {$[0.503 ; 0.607]^{*}$} & {$[0.503 ; 0.607]^{*}$} & {$[0.503 ; 0.608]^{*}$} & {$[0.501 ; 0.607]^{*}$} \\
a2 & 0.511 & 0.595 & 0.346 & 0.542 \\
& {$[0.266 ; 0.756]^{*}$} & {$[0.426 ; 0.764]^{*}$} & {$[0.008 ; 0.685]^{*}$} & {$[0.300 ; 0.784]^{*}$} \\
c2 & 0.355 & 0.005 & 0.457 & 0.002 \\
& {$[0.072 ; 0.638]^{*}$} & {$[-0.316 ; 0.326]$} & {$[0.267 ; 0.647]^{*}$} & {$[-0.391 ; 0.395]$} \\
e2 & 0.662 & 0.690 & 0.721 & 0.780 \\
& {$[0.615 ; 0.709]^{*}$} & {$[0.641 ; 0.739]^{*}$} & {$[0.670 ; 0.771]^{*}$} & {$[0.724 ; 0.836]^{*}$} \\
a11 & 0.368 & 0.348 & 0.372 & 0.311 \\
& {$[0.262 ; 0.474]^{*}$} & {$[0.256 ; 0.441]^{*}$} & {$[0.273 ; 0.470]^{*}$} & {$[0.214 ; 0.409]^{*}$} \\
c11 & 0.000 & 0.000 & 0.000 & 0.000 \\
& {$[0.000 ; 0.000]$} & {$[0.000 ; 0.000]$} & {$[0.000 ; 0.000]$} & {$[0.000 ; 0.000]$} \\
e11 & 0.000 & 0.000 & 0.000 & 0.000 \\
MZ/DZ & {$[0.000 ; 0.000]$} & {$[0.000 ; 0.000]$} & {$[0.000 ; 0.000]$} & {$[0.000 ; 0.000]$} \\
pairs & $827 / 917$ & $827 / 917$ & $827 / 913$ & $825 / 913$ \\
\hline
\end{tabular}

From the perspective of political equality, it is quite interesting to know whether a person's social background can amplify or compensate for genetic (dis-)advantages regardless of whether the effect of education on political engagement is causal or not. To investigate this possibility, we therefore turn to an investigation of exactly how the effect of education is moderated by family politicization and/or family stability.

THE FOREST: THE MODERATING INFLUENCE OF FAMILY STABILITY AND POLITICIZATION

\section{Family consistency}

For all measures of political engagement, the (genetically confounded) effect of education is significantly moderated by family consistency and the effect is negative, as is shown in Table 2 . This implies that as family stability increases, the amount of genetic confounding decreases. It is thus not the case that genetic advantages and growing up in a family with high levels of education work together to create political (in)equality: They complement each other. For those individuals who are less genetically endowed, the family environment compensates for the disadvantage, whereas for those who grow up in a family with low levels of education, the family does not.

To illustrate the magnitude of the relationship, we calculated the marginal effect using Equation 3 where family consistency varies from +/- two standard deviations from the mean of zero. Figure 2 illustrates that for our four measures of political engagement, there is almost no genetic effect of education on political engagement when family consistency is two standard deviations above the mean; although it is just exactly significant for political interest $(95 \%$ CI [0.017;0.420] and consumption of news (95\% CI [0.014;0.440], so here we cannot rule out a (potentially very small) effect. 
TABLE 2: Moderation of the effect of education on political interest, consumption of news, and participation by family consistency

\begin{tabular}{ccccc}
\hline Parameter & Political interest & Consumption of news & Participation & External efficacy \\
\hline \multirow{2}{*}{ a1 } & 0.494 & 0.461 & 0.506 & 0.429 \\
& {$[0.311 ; 0.677]^{*}$} & {$[0.258 ; 0.663]^{*}$} & {$[0.370 ; 0.642]^{*}$} & {$[0.257 ; 0.601]^{*}$} \\
c1 & 0.449 & 0.416 & 0.425 & 0.378 \\
& {$[0.238 ; 0.660]^{*}$} & {$[0.154 ; 0.678]^{*}$} & {$[0.274 ; 0.575]^{*}$} & {$[0.163 ; 0.593]^{*}$} \\
e1 & 0.688 & 0.720 & 0.717 & 0.795 \\
& {$[0.639 ; 0.738]^{*}$} & {$[0.663 ; 0.778]^{*}$} & {$[0.670 ; 0.764]^{*}$} & {$[0.739 ; 0.851]^{*}$} \\
a2 & 0.472 & 0.511 & 0.513 & 0.501 \\
& {$[0.164 ; 0.780]^{*}$} & {$[0.201 ; 0.822]^{*}$} & {$[0.282 ; 0.745]^{*}$} & {$[0.201 ; 0.801]^{*}$} \\
c2 & 0.337 & 0.275 & 0.340 & 0.297 \\
& {$[0.050 ; 0.625]^{*}$} & {$[-0.030 ; 0.580]$} & {$[0.061 ; 0.619]^{*}$} & {$[-0.002 ; 0.595]$} \\
e2 & 0.562 & 0.558 & 0.561 & 0.559 \\
& {$[0.506 ; 0.617]^{*}$} & {$[0.504 ; 0.613]^{*}$} & {$[0.506 ; 0.617]^{*}$} & {$[0.504 ; 0.613]^{*}$} \\
a11 & 0.452 & 0.453 & 0.391 & 0.450 \\
& {$[0.287 ; 0.617]^{*}$} & {$[0.262 ; 0.644]^{*}$} & {$[0.274 ; 0.508]^{*}$} & {$[0.270 ; 0.630]^{*}$} \\
c11 & 0.000 & 0.000 & 0.000 & 0.000 \\
& {$[0.000 ; 0.000]$} & {$[0.000 ; 0.000]$} & {$[0.000 ; 0.000]$} & {$[0.000 ; 0.000]$} \\
e11 & 0.000 & 0.000 & 0.000 & 0.000 \\
moda11 & {$[0.000 ; 0.000]$} & {$[0.000 ; 0.000]$} & {$[0.000 ; 0.000]$} & {$[0.000 ; 0.000]$} \\
MZ/DZ & -0.117 & -0.113 & -0.162 & -0.128 \\
pairs & $58 ; 75 ;-0.059]^{*}$ & {$[-0.173 ;-0.054]^{*}$} & {$[-0.223 ;-0.100]^{*}$} & {$[-0.189 ;-0.068]^{*}$} \\
\hline
\end{tabular}

Sample sizes are lower for these results compared to the model with no moderation, since we lose a twin pair if a twin is missing information on this construct because it is treated as an independent variable, whereas we use FIML to estimate the dependent parameters

Figure 2: Effect of education on various constructs
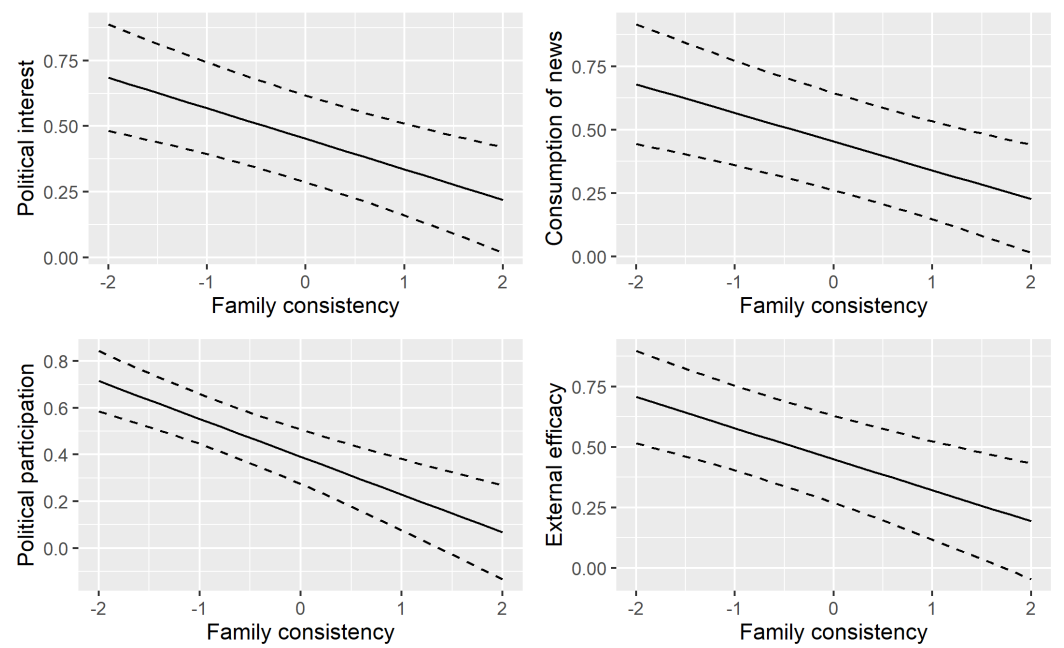


\section{Family politicization}

The results for family politicization mirror those obtained for family consistency: The (genetically confounded) effect of education on political engagement decreases as the level of family politicization increases, as signified by the significant interaction effect for all four constructs, illustrated in Table 3.

TABLE 3: Moderation of the effect of education on political interest, consumption of news, and participation by family politicization

\begin{tabular}{ccccc}
\hline Parameter & Political interest & Consumption of news & Participation & External efficacy \\
\hline \multirow{2}{*}{ a1 } & 0.567 & 0.371 & 0.465 & 0.208 \\
& {$[0.355 ; 0.779]^{*}$} & {$[0.115 ; 0.627]^{*}$} & {$[0.281 ; 0.650]^{*}$} & {$[0.075 ; 0.341]^{*}$} \\
c1 & 0.142 & 0.392 & 0.389 & 0.489 \\
& {$[-0.186 ; 0.469]$} & {$[0.072 ; 0.712]^{*}$} & {$[0.168 ; 0.609]^{*}$} & {$[0.348 ; 0.630]^{*}$} \\
e1 & 0.674 & 0.718 & 0.703 & 0.799 \\
& {$[0.619 ; 0.730]^{*}$} & {$[0.655 ; 0.781]^{*}$} & {$[0.647 ; 0.759]^{*}$} & {$[0.742 ; 0.855]^{*}$} \\
a2 & 0.673 & 0.590 & 0.592 & 0.051 \\
& {$[0.393 ; 0.954]^{*}$} & {$[0.147 ; 1.033]^{*}$} & {$[0.296 ; 0.887]^{*}$} & {$[-0.176 ; 0.279]$} \\
c2 & 0.203 & 0.154 & 0.238 & 0.091 \\
& {$[-0.132 ; 0.538]$} & {$[-0.177 ; 0.485]$} & {$[-0.093 ; 0.569]$} & {$[-0.217 ; 0.400]$} \\
e2 & 0.546 & 0.546 & 0.547 & 0.546 \\
& {$[0.478 ; 0.614]^{*}$} & {$[0.479 ; 0.614]^{*}$} & {$[0.480 ; 0.615]^{*}$} & {$[0.479 ; 0.613]^{*}$} \\
a11 & 0.266 & 0.440 & 0.388 & 0.748 \\
& {$[0.055 ; 0.477]^{*}$} & {$[0.125 ; 0.755]^{*}$} & {$[0.199 ; 0.577]^{*}$} & {$[0.570 ; 0.926]^{*}$} \\
c11 & 0.000 & 0.000 & 0.000 & 0.000 \\
& {$[0.000 ; 0.000]$} & {$[0.000 ; 0.000]$} & {$[0.000 ; 0.000]$} & {$[0.000 ; 0.000]$} \\
e11 & 0.000 & 0.000 & 0.000 & 0.000 \\
& {$[0.000 ; 0.000]$} & {$[0.000 ; 0.000]$} & {$[0.000 ; 0.000]$} & {$[0.000 ; 0.000]$} \\
moda11 & -0.091 & -0.087 & -0.132 & -0.071 \\
MZ/DZ & {$[-0.167 ;-0.016]^{*}$} & {$[-0.159 ;-0.015]^{*}$} & {$[-0.209 ;-0.056]^{*}$} & {$[-0.122 ;-0.021]^{*}$} \\
pairs & $438 / 462$ & $438 / 462$ & $438 / 462$ & $438 / 462$ \\
\hline
\end{tabular}

Sample sizes are lower for these results compared to 1 , since we lose a twin pair if a twin is missing information on this construct because it is treated as an independent variable, whereas we use FIML to estimate the dependent parameters. In addition we only have information on politicization for a subset of the twins from a previous survey, as discussed in the "Measures" section

Figure 3: Effect of education on various constructs
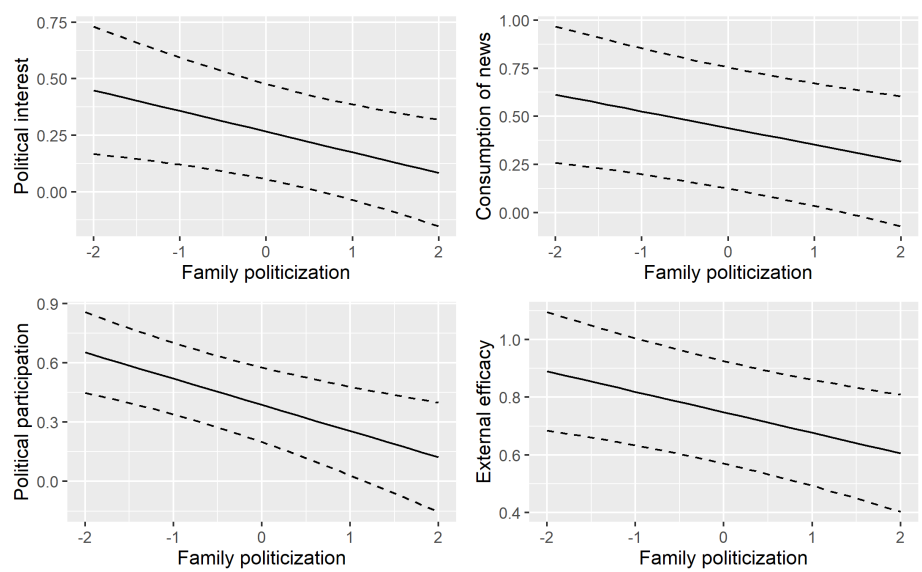
We have also calculated marginal effects for the impact of education on political engagement to illustrate the overall effect across different levels of the moderator. This is illustrated in Figure 3. For all measures of political engagement, except external efficacy, the effect of education is zero when family politicization is two standard deviations above the mean of zero.

\section{Compensation but no Matthew effect}

It can sometimes be difficult to fully comprehend exactly what is at stake when only looking at the marginal effects. To further elaborate on the effects of family politicization and family consistency, we have calculated predicted values at $+/$ - two standard deviations above and below the mean for the moderator for the effect of education on political interest. This is illustrated in Figure 4.

Figure 4: Effect of education on political interest at varying levels of politicization and consistency

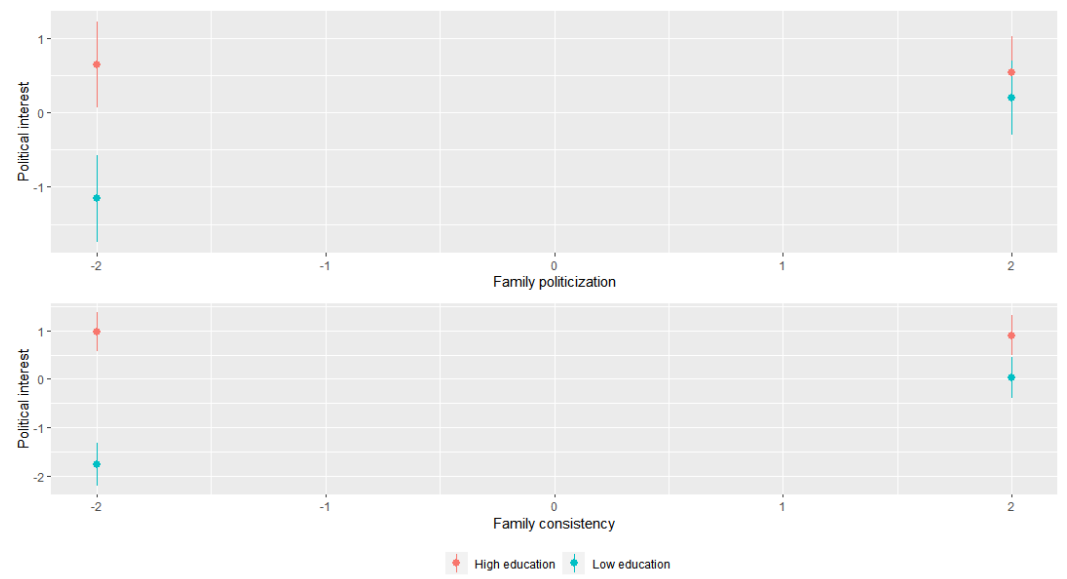

We can clearly see that when family consistency and family politicization are low (i.e. at -2 standard deviations below the mean), there is a sizeable difference in the effect of education on political interest. When one's level of education is two standard deviations above the mean ("High education"), the predicted level of political interest is almost two standard deviations above the mean. For those with an education level that is two standard deviations below the mean, the predicted level of political interest is almost two standard deviations below the mean. These important substantive differences are statistically significant. Conversely, when we compare those with "High" and "Low" education when the level of politicization or consistency is high, we find little or no difference in terms of the predicted levels of engagement. If we had observed a Matthew effect, there would be positive externalities to having both a high level of education and a highly politicized family environment.

\section{DISCUSSION AND CONCLUSION}

In this paper, we have demonstrated that there is no causal effect of education on political engagement. Although this finding might have been extremely provocative had we presented it in 2007, in the past decade or so many scholars (Persson 2015; Kam and Palmer 2008) have 
questioned the causal role of education on a range of political behaviors and attitudes, which makes this finding almost trivial.

The reason why scholars continually revisit this finding and its implication is of course because of the important role education has traditionally played in ensuring political equality and the important role education is perceived to play in a democratic society (Converse 1972). By solely focusing on whether or not the effect of education on political engagement is (completely or partially) confounded or not, we risk missing the forest for the trees.

Here, we have demonstrated that the effect of education on a range of psychological and behavioral measures of political engagement is mostly genetically confounded and not confounded by the shared environment, such as parental education and socioeconomic status. This is highly surprising since most scholars focusing on the parental transmission of values (Jennings and Niemi 1968) have focused on the social aspects that give rise to the transmission of values and behaviors and can, in turn, lead to inequalities in political engagement and ultimately political inequality within a political system. One way to interpret these results is by drawing on the work of the French sociologist Pierre Bourdieu, who has argued that the educational system serves to reproduce existing social inequalities (Bourdieu 1984) through social capital. What we are able to demonstrate here is that this does not appear to be happening. Indeed, for none of our measures of political engagement does the shared environment confound the effect of education on political engagement. Instead, we found that genetic differences seem to be the driving force. An interpretation consistent with this finding is that our sample is in Denmark, which is a country with low social barriers to entry in the educational system. Since there are few social barriers to entry in the educational system, what matters are genetic differences in the motivation and/or capacity to pursue a long-term higher education. Future studies should investigate the important interplay between genetic and environmental factors in shaping political engagement in less equal societies with more severe barriers to entry in the educational system.

We have also demonstrated that the (non-causal) effect is moderated by family consistency and family politicization: When either family consistency or family politicization is high, the genetic confounding disappears. This finding is consistent with family background compensating for genetic differences leading to differences in educational outcomes and in turn differences in political engagement. In fact, when family politicization or family consistency are at high levels, genetic confounding completely disappears. Family background can thus completely compensate for the effect of genetic disadvantages. Using an adoptee design, Willoughby et al. (2020) (see also Oskarsson, Dawes, and Lindgren (2018)) are able to demonstrate that parent-to-child influences are both genetic and environmental in origin. The influences of the moderators presented here are thus likely not only environmental in origin. The results presented here are, however, consistent with the results from Lindgren, Oskarsson, and Persson (2019), who demonstrate that although there seems to be no overall average effect of education on voter turnout, education has an effect on turnout among those from low-socioeconomic status households. In this paper, we were able to demonstrate why this might be happening: Family background can compensate for genetic disadvantages. At a more meta level, these results are also an important reminder that genetic determinism is always too simple to be useful. What is needed is a birds-eye view of the complex interplay between genetic and environmental factors that allows us to not miss the forest for the trees. 


\section{REFERENCES}

Alford, John R., Carolyn Funk, and John R. Hibbing. 2005. “Are Political Orientations Genetically Transmitted?” American Political Science Review 99 (02): 153-167.

Bandura, Albert. 1969. "Social-learning theory of identificatory processes." Handbook of socialization theory and research 213:262.

1986. "Social foundations of thought and action." Englewood Cliffs, NJ 1986:23-28.

Barth, Daniel, Nicholas W Papageorge, and Kevin Thom. 2020. "Genetic endowments and wealth inequality." Journal of Political Economy 128 (4): 1474-1522.

Belsky, Daniel W, Benjamin W Domingue, Robbee Wedow, Louise Arseneault, Jason D Boardman, Avshalom Caspi, Dalton Conley, Jason M Fletcher, Jeremy Freese, Pamela Herd, et al. 2018. "Genetic analysis of social-class mobility in five longitudinal studies." Proceedings of the National Academy of Sciences 115 (31): E7275-E7284.

Berinsky, Adam, and Gabriel Lenz. 2011. "Education and Political Participation: Exploring the Causal Link." Political Behavior, 357-373.

Bollen, Kenneth A. 1989. "Structural equations with latent variables Wiley.” New York.

Bourdieu, Pierre. 1984. Distinction: A social critique of the judgement of taste. Harvard university press.

Brambor, Thomas, William Roberts Clark, and Matt Golder. 2006. "Understanding interaction models: Improving empirical analyses.” Political analysis, 63-82.

Burden, Barry, Pamela Herd, Bradley Jones, and Donald Moynihan. 2020. "Education, early life, and political participation: New evidence from a sibling model." Research \& Politics.

Campbell, D. E. 2009. "Civic Engagement and Education: An Empirical Test of the Sorting Model." American Journal of Political Science 53 (4): 771-786.

Christensen, Kaare, Inge Petersen, Axel Skytthe, Anne Maria Herskind, Matt McGue, and Paul Bingley. 2006. "Comparison of academic performance of twins and singletons in adolescence: follow-up study." bmj 333 (7578): 1095.

Converse, Philip E. 1972. "Change in the American electorate." In The human meaning of social change, edited by Angus Campbell and Philip E. Converse, 263-339. New York: Russel Sage Foundation.

Damian, Rodica Ioana, Rong Su, Michael Shanahan, Ulrich Trautwein, and Brent W Roberts. 2015. "Can personality traits and intelligence compensate for background disadvantage? Predicting status attainment in adulthood." Journal of personality and social psychology 109 (3): 473.

Delli Carpini, Michael X, and Scott Keeter. 1996. What Americans Know about Politics and Why It Matters. Yale University Press. IS B N: 9780300062564. http://www.jstor.org/stable/j. ctt1cc2kv1. 
Dinesen, Peter Thisted, Christopher T. Dawes, Magnus Johannesson, Robert Klemmensen, Patrik Magnusson, Asbjørn Sonne Nørgaard, Inge Petersen, and Sven Oskarsson. 2016. "Estimating the Impact of Education on Political Participation: Evidence from Monozygotic Twins in the United States, Denmark and Sweden." Political Behavior, 1-23.

Enders, Craig K. 2010. Applied missing data analysis. Guilford press.

Falconer, Douglas Scott. 1996. Introduction to quantitative genetics. Pearson.

Fowler, James H., Laura A. Baker, and Christopher T. Dawes. 2008. "Genetic Variation in Political Participation.” American Political Science Review 102 (2): 233-248.

Gidengil, Elisabeth, Lasse Tarkiainen, Hanna Wass, and Pekka Martikainen. 2019. "Turnout and Education: Is Education Proxying for Pre-Adult Experiences Within the Family?" Political Science Research and Methods, 349-365.

Hallquist, Michael N., and Joshua F. Wiley. 2018. "MplusAutomation: An R Package for Facilitating Large-Scale Latent Variable Analyses in Mplus." Structural Equation Modeling, 1-18. https://doi.org/10.1080/10705511.2017.1402334. https://www.tandfonline.com/doi/ full/10.1080/10705511.2017.1402334.

Hebbelstrup Rye Rasmussen, Stig, Aaron Weinschenk, Asbjørn Sonne Nørgaard, Jacob von Bornemann Hjelmborg, and Robert Klemmensen. 2021. "Educational Attainment Has a Causal Effect on Economic, But Not Social Ideology: Evidence from Discordant Twins." Political Studies, 00323217211008788.

Henderson, John, and Sara Chatfield. 2011. "Who matches? Propensity scores and bias in the causal effects of education on participation.” Journal of Politics 73 (3): 646-658.

Highton, B. 2009. "Revisiting the Relationship between Educational Attainment and Political Sophistication.” Journal of Politics 71 (4): 1564-1576.

Hyman, Herbert. 1959. Political socialization. New York: Free Press. Book.

Jennings, M. K., L. Stoker, and J. Bowers. 2009. "Politics across Generations: Family Transmission Reexamined.” Journal of Politics 71 (3): 782-799.

Jennings, M. Kent, and Richard G. Niemi. 1968. "The Transmission of Political Values from Parent to Child." The American Political Science Review 62 (1): 169-184.

Johnson, W., I. J. Deary, K. Silventoinen, P. Tynelius, and F. Rasmussen. 2010. "Family Background Buys an Education in Minnesota but Not in Sweden." Psychological Science 21 (9): 1266-1273.

Kam, Cindy, and Carl Palmer. 2008. "Reconsidering the effects of education on political participation.” Journal of Politics 70 (3): 612-631.

2011. "Rejoinder: Reinvestigating the Causal Relationship between Higher Education and Political Participation.” Journal of Politics 73 (7): 659-663.

Klemmensen, Robert, Sara B Hobolt, Peter T Dinesen, Axel Skytthe, and Asbjørn Sonne Nørgaard. 2012. "The Danish political twin study: Political traits in Danish twins and the general population." Twin Research and Human Genetics 15 (01): 74-78. 
Lindgren, Karl-Oskar, Sven Oskarsson, and Mikael Persson. 2019. "Enhancing electoral equality: can education compensate for family background differences in voting participation?" American Political Science Review 113 (1): 108-122.

Loftus, Geoffrey R. 1978. "On interpretation of interactions.” Memory \& Cognition 6 (3): 312-319.

Mayer, Alexander K. 2011. "Does education increase political participation?" The Journal of Politics 73 (03): 633-645.

McArdle, J Jack, and Roderick P McDonald. 1984. "Some algebraic properties of the reticular action model for moment structures." British Journal of Mathematical and Statistical Psychology 37 (2): 234-251.

McGue, Matt, and Thomas J Bouchard. 1984. "Adjustment of twin data for the effects of age and sex." Behavior genetics 14 (4): 325-343.

McGue, Matt, Merete Osler, and Kaare Christensen. 2010. "Causal inference and observational research: The utility of twins." Perspectives on psychological science 5 (5): 546-556.

McGue, Matt, Emily A Willoughby, Aldo Rustichini, Wendy Johnson, William G Iacono, and James J Lee. 2020. "The contribution of cognitive and noncognitive skills to intergenerational social mobility." Psychological Science 31 (7): 835-847.

Muthén, LK, and BO Muthén. 2017. Mplus User's Guide. Eighth Edition.

Neale, MCCL, and Lon R Cardon. 2013. Methodology for genetic studies of twins and families. Vol. 67. Springer Science \& Business Media.

Neundorf, Anja, Richard G. Niemi, and Kaat Smets. 2016. "The Compensation Effect of Civic Education on Political Engagement: How Civics Classes Make Up for Missing Parental Socialization.” Political Behavior 38 (4): 921-949.

Nie, Norman H., Jane Junn, and Kenneth Stehlik-Barry. 1996. Education and democratic citizenship in America. Chicago: The University of Chicago Press. Book.

Niemi, Richard G, Stephen C Craig, and Franco Mattei. 1991. "Measuring internal political efficacy in the 1988 National Election Study." The American Political Science Review, 1407-1413.

Oskarsson, Sven, Rafael Ahlskog, Christopher Dawes, and Karl-Oskar Lindgren. 2020. "Persistent Inequalities: The Origins of Intergenerational Associations in Voter Turnout," https://conpol. org/wp-content/uploads/2020/06/AdoptionPaper.pdf.

Oskarsson, Sven, Christopher T Dawes, and Karl-Oskar Lindgren. 2018. "It runs in the family." Political Behavior 40 (4): 883-908.

Oskarsson, Sven, Peter Thisted Dinesen, Christopher T. Dawes, Magnus Johannesson, and Patrik K. E. Magnusson. 2017. "Education and Social Trust: Testing a Causal Hypothesis Using the Discordant Twin Design.” Political Psychology, n/a-n/a.

Persson, Mikael. 2014. "Testing the Relationship Between Education and Political Participation Using the 1970 British Cohort Study.” Political Behavior 36 (4): 877-897. 
Persson, Mikael. 2015. "Education and Political Participation." British Journal of Political Science 45 (03): 689-703.

Plomin, Robert, and Denise Daniels. 1987. "Why are children in the same family so different from one another?" Behavioral and brain Sciences 10 (1): 1-16.

Purcell, Shaun. 2002. "Variance components models for gene-environment interaction in twin analysis." Twin Research and Human Genetics 5 (6): 554-571.

Rasmussen, Stig Hebbelstrup Rye. 2015a. "Education or Personality Traits and Intelligence as Determinants of Political Knowledge?" Political Studies.

. 2015b. "Education or Personality Traits and Intelligence as Determinants of Political Knowledge?" Political Studies, DOI 10.1111/1467-9248.12214.

_. 2016. "Cognitive Ability Rivals the Effect of Political Sophistication on Ideological Voting." Political Research Quarterly 69 (4): 773-787.

Rasmussen, Stig Hebbelstrup Rye, and Asbjørn Sonne Nørgaard. 2018. "When and why does education matter? Motivation and resource effects in political efficacy." European Journal of Political Research 57 (1): 24-46. Iss N: 1475-6765.

Robinson, Darrel. 2020. "Education, Family Background, and Political Knowledge: A Test of the Compensation Hypothesis with Identical Twins.” Political Studies 68 (2): 350-369.

Sondheimer, Rachel Milstein, and Donald P Green. 2010. "Using experiments to estimate the effects of education on voter turnout." American Journal of Political Science 54 (1): 174-189.

Turkheimer, Eric, and K Paige Harden. 2014. "Behavior genetic research methods." Handbook of research methods in social and personality psychology, 159-187.

Verba, Sidney, Kay Lehman Schlozman, and Henry E Brady. 1995. Voice and equality: Civic voluntarism in American politics. Harvard University Press.

Weinschenk, Aaron, Christopher T. Dawes, and Sven Oskarsson. 2020. "Does Education Instill Civic Duty? Evidence from Monozygotic Twins in the United States and Sweden." International Journal of Public Opinion Research.

Weinschenk, Aaron C., and Christopher T. Dawes. 2019. "The Effect of Education on Political Knowledge: Evidence From Monozygotic Twins.” American Politics Research 47 (3): 530 548.

Wickham, Hadley. 2016. ggplot2: Elegant Graphics for Data Analysis. Springer-Verlag New York. IS B N: 978-3-319-24277-4. https://ggplot2.tidyverse.org.

Willoughby, Emily A, Alexandros Giannelis, Robert Klemmensen, Asbjørn S Nørgaard, William G Iacono, James J Lee, Matt McGue, et al. 2020. "Parent contributions to the development of political attitudes in adoptive and non-adoptive families." 


\section{APPENDIX 1}

TABLE 1: Descriptive statistics in the original metric

\begin{tabular}{cccccc}
\hline Construct & Count & Mean & Sd & Min & Max \\
\hline Education & 2539.0 & 2.94 & 1.58 & 0.0 & 5.0 \\
Political interest & 2469.0 & 2.68 & 0.73 & 1.0 & 4.0 \\
Consumption of news & 2469.0 & 3.76 & 1.21 & 1.0 & 5.0 \\
Participation & 2409.0 & 2.56 & 0.62 & 1.0 & 4.0 \\
External efficacy & 2374.0 & 2.59 & 0.78 & 1.0 & 4.0 \\
Politicization & 1792.0 & 2.26 & 0.85 & 1.0 & 4.0 \\
Parental education & 2312.0 & 4.31 & 2.0 & 1.0 & 7.0 \\
Age & 4911.0 & 28.52 & 6.26 & 20.0 & 39.0 \\
Male & 4911.0 & 0.45 & 0.5 & 0.0 & 1.0 \\
\hline
\end{tabular}

TABLE 2: Descriptive statistics in standardized metric

\begin{tabular}{cccccc}
\hline Construct & Count & Mean & Sd & Min & Max \\
\hline Education & 2539.0 & 0.59 & 0.32 & 0.0 & 1.0 \\
Political interest & 2469.0 & 0.56 & 0.24 & 0.0 & 1.0 \\
Consumption of news & 2469.0 & 0.69 & 0.3 & 0.0 & 1.0 \\
Participation & 2409.0 & 0.52 & 0.21 & 0.0 & 1.0 \\
External efficacy & 2374.0 & 0.53 & 0.26 & 0.0 & 1.0 \\
Politicization & 1792.0 & 0.42 & 0.28 & 0.0 & 1.0 \\
Parental education & 2312.0 & 0.55 & 0.33 & 0.0 & 1.0 \\
Age & 4911.0 & 0.45 & 0.33 & 0.0 & 1.0 \\
Male & 4911.0 & 0.45 & 0.5 & 0.0 & 1.0 \\
\hline
\end{tabular}


TABLE 3: Fit statistics for Cholesky models for political interest

\begin{tabular}{ccccc}
\hline AIC & $\begin{array}{c}\text { Chi-square } \\
\text { value }\end{array}$ & $\begin{array}{c}\text { Chi-square } \\
\text { degrees of freedom }\end{array}$ & Constraint & $\begin{array}{c}\text { Chi-square } \\
\text { difference testing }\end{array}$ \\
\hline 13280.85 & 40.829 & 29.0 & None & 1.000 \\
\hline 13285.78 & 47.754 & 30.0 & ch1 $=0 ;$ & 0.008 \\
\hline 13280.13 & 42.101 & 30.0 & ch2 $=0 ;$ & 0.259 \\
\hline 13279.24 & 41.211 & 30.0 & ch3 $=0 ;$ & 0.537 \\
\hline 13369.89 & 133.859 & 31.0 & ch1 $=0 ; \operatorname{ch} 2=0 ;$ & 0.000 \\
\hline 13278.21 & 42.188 & 31.0 & ch2 $=0 ; \operatorname{ch} 3=0 ;$ & 0.507 \\
\hline 13289.78 & 53.756 & 31.0 & ch $1=0 ; \operatorname{ch} 3=0 ;$ & 0.002 \\
\hline 13428.04 & 194.011 & 32.0 & ch1 $=0 ; \operatorname{ch} 2=0 ; \operatorname{ch} 3=0 ;$ & 0.000 \\
\hline
\end{tabular}

TABLE 4: Fit statistics for Cholesky models for consumption of news

\begin{tabular}{ccccc}
\hline AIC & $\begin{array}{c}\text { Chi-square } \\
\text { value }\end{array}$ & $\begin{array}{c}\text { Chi-square } \\
\text { degrees of freedom }\end{array}$ & Constraint & $\begin{array}{c}\text { Chi-square } \\
\text { difference testing }\end{array}$ \\
\hline 13291.34 & 47.475 & 30.0 & ch2 $=0 ;$ & 1.000 \\
\hline 13289.46 & 47.596 & 31.0 & $\operatorname{ch} 2=0 ; \operatorname{ch} 3=0 ;$ & 0.728 \\
\hline 13387.24 & 145.371 & 31.0 & $\operatorname{ch} 1=0 ; \operatorname{ch} 2=0 ;$ & 0.000 \\
\hline 13436.32 & 196.455 & 32.0 & $\operatorname{ch} 1=0 ; \operatorname{ch} 2=0 ; \operatorname{ch} 3=0 ;$ & 0.000 \\
\hline
\end{tabular}

TABLE 5: Fit statistics for Cholesky models for political participation

\begin{tabular}{ccccc}
\hline AIC & $\begin{array}{c}\text { Chi-square } \\
\text { value }\end{array}$ & $\begin{array}{c}\text { Chi-square } \\
\text { degrees of freedom }\end{array}$ & Constraint & $\begin{array}{c}\text { Chi-square } \\
\text { difference testing }\end{array}$ \\
\hline 13225.38 & 31.581 & 29.0 & None & 1.000 \\
\hline 13228.20 & 36.397 & 30.0 & ch1 $=0 ;$ & 0.028 \\
\hline 13225.20 & 33.393 & 30.0 & ch2 $=0 ;$ & 0.178 \\
\hline 13225.30 & 33.492 & 30.0 & ch3 $=0 ;$ & 0.167 \\
\hline 13299.16 & 109.352 & 31.0 & ch1 $=0 ;$ ch2 $=0 ;$ & 0.000 \\
\hline 13224.16 & 34.354 & 31.0 & ch2 $=0 ; \operatorname{ch} 3=0 ;$ & 0.250 \\
\hline 13236.35 & 46.551 & 31.0 & ch $1=0 ;$ ch3 $=0 ;$ & 0.001 \\
\hline 13365.59 & 177.792 & 32.0 & ch1 $=0 ; \operatorname{ch} 2=0 ;$ ch3 $=0 ;$ & 0.000 \\
\hline
\end{tabular}

TABLE 6: Fit statistics for Cholesky models for external efficacy

\begin{tabular}{ccccc}
\hline AIC & $\begin{array}{c}\text { Chi-square } \\
\text { value }\end{array}$ & $\begin{array}{c}\text { Chi-square } \\
\text { degrees of freedom }\end{array}$ & Constraint & $\begin{array}{c}\text { Chi-square } \\
\text { difference testing }\end{array}$ \\
\hline 13266.03 & 36.987 & 30.0 & ch2 $=0 ;$ & 1.000 \\
\hline 13266.26 & 39.216 & 31.0 & ch2=0; $\operatorname{ch} 3=0 ;$ & 0.135 \\
\hline 13344.26 & 117.210 & 31.0 & ch $1=0 ; \operatorname{ch} 2=0 ;$ & 0.000 \\
\hline 13370.77 & 145.718 & 32.0 & ch1 $=0 ; \operatorname{ch} 2=0 ; \operatorname{ch} 3=0 ;$ & 0.000 \\
\hline
\end{tabular}


APPENDix 2: QuESTION WORDING

\section{Measures of education}

What is your schooling ?7

- Primary school 7 years or less

- Primary school 8-9 years

- Primary school 9 years

- 10th grade, no exam

- 10th grade

- High school, no exam

- High school

- Other type of schooling

- Don't know

Which vocational or higher education have you completed?

- No education

- Unskilled worker

- Apprenticeship

- Vocational education

- Short-term higher education

- Medium-term higher education

- Long-term higher education

- Other education

- Don’t know

\section{Political interest}

\section{How interested are you in politics?}

Answer categories were: Very interested, Somewhat interested, Not very interested, Not interested

${ }^{7}$ The two educational variables are recoded into one continuous variable. This strategy is chosen to reflect the "years of school education." Thus, if someone indicated "No education" for vocational education, this is replaced with the category from the question "What is your schooling?" The categories are recoded into these categories: 1. 9-10 years or less (primary school) 2. 10-11 years (unskilled worker, apprenticeship and vocational education) 3 . 11-12 years of education (high school) 4. 13-14 years of education (short-term higher education) 5. 14-16 years of education (medium-term higher education) 6. 17-18 years of education (long-term higher education) 
Consumption of news

How often do you follow politics on television, radio, or in the newspapers?

Answer categories were: Every day, Several times a week, 1-2 times a week, Rarely, Never

\section{Participation}

Have you [done act]?

The acts were: Signed a petition, Boycotted or deliberately bought certain goods, Participated in a demonstration, Participated in a political meeting

Answer categories were: Have done within the last year, Have done it at an earlier time, Have not done it but might do it, Have not done it and will never do it, Don't know

\section{External efficacy}

People like me have no say in what the government does I don't think public officials care much what people like me think

Answer categories were: Completely agree, Partially agree, Partially disagree, Don't know

\section{Politicization}

Growing up, how often did you discuss politics with your family (apart from your twin)?

Answer categories were: Never, Rarely, Now and then, Often

\section{Parental education}

Which vocational education did the main provider have?

- No education

- Unskilled worker

- Apprenticeship

- Vocational education

- Short-term higher education

- Medium-term higher education

- Long-term higher education

- Other education

- Don't know 


\section{Appendix 3: Model elaboration}

The figure below illustrates a bivariate (Cholesky) twin model, where X could e.g. be education and Y could be (some form of) political engagement.

Figure 1: Bivariate cholesky decomposition

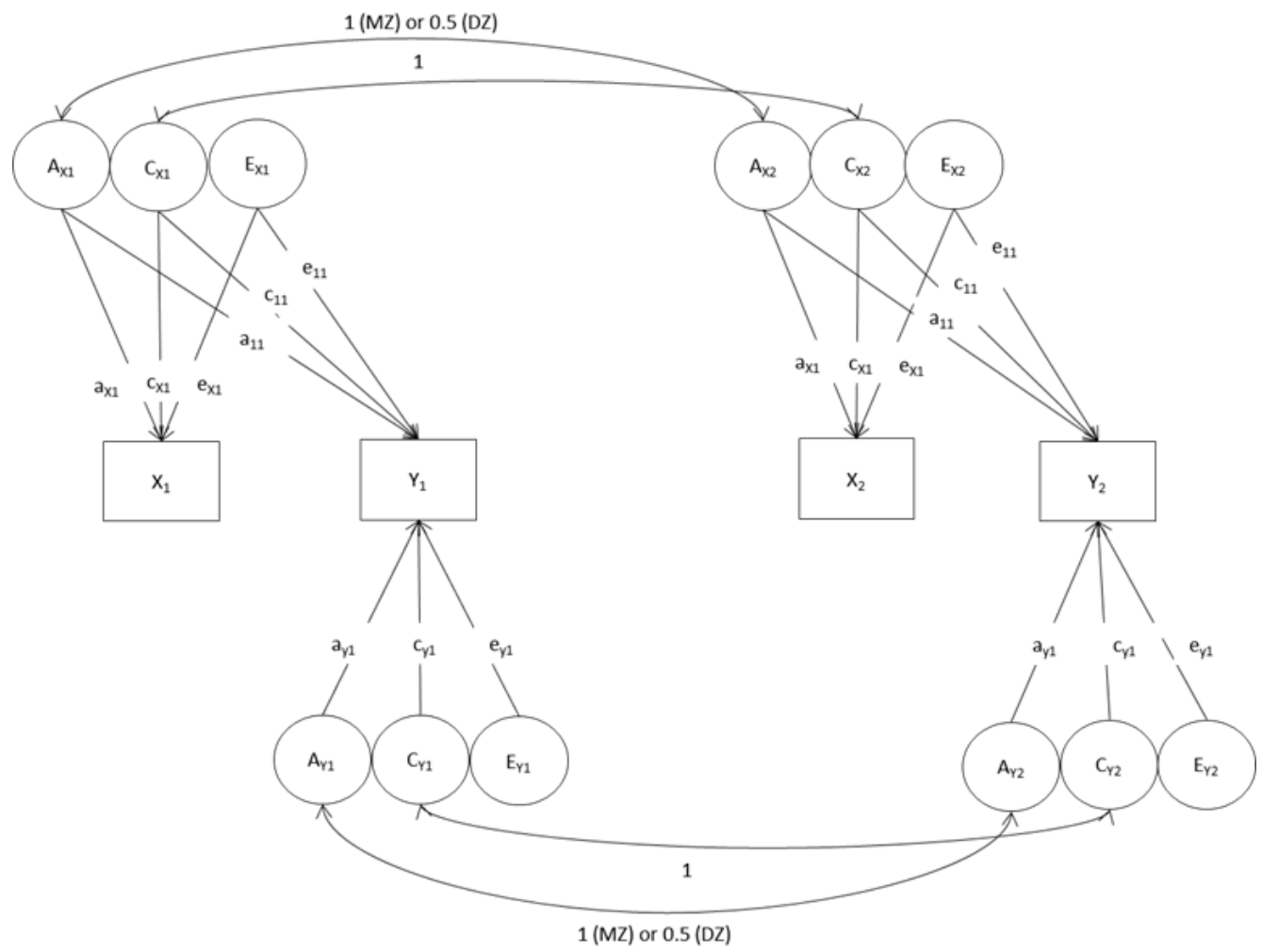


In this model we have imposed these constraints:

- The shared environment correlation for both $\mathrm{MZ}$ and $\mathrm{DZ}$ twin pairs is constrained to be 1 (this is the so-called equal environment assumption)

- The genetic within correlation between MZ twin pairs is 1 whereas the genetic within correlation between DZ twin pairs is 0.5

- The variance of each of the latent variables $\mathrm{A}, \mathrm{C}$, and $\mathrm{E}$ are constrained to 1

- The variance components are assumed to be mutually exclusive (i.e. no paths between them) and exhaustive (i.e. no residual variance, since the residual variance is contained in the E term)

- There is a clear ordering of the constructs such that the latent constructs from education affect political attitudes but not the other way around

An SEM model can be represented by using these three matrices:

- A matrix of asymmetric paths - A

- A matrix for symmetric paths - S

- A matrix for filtering out latent variables - F

These matrices for Figure 1 are shown below and denoted A, S, F. These matrices can be used to calculate the model-implied variance covariance matrix $\Sigma_{\text {implied }}$ using the formula from $F(I-A)^{-1} S(I-A)^{-1^{\prime}} F^{\prime}$ (McArdle and McDonald 1984)

Typically SEM software then uses maximum likelihood to make the difference between the model-implied variance-covariance matrix and the empirical variance-covariance matrix (Bollen 1989, chapter 4). The observed variance-covariance matrix for two observed variables X (e.g. education) and $\mathrm{Y}$ (e.g. political participation) is illustrated in the matrix below, where $X_{11}$ refers to Twin 1's values on the $\mathrm{X}$ variable and $Y_{11}$ refers to the values of the $\mathrm{Y}$ variable for Twin 1 and $X_{12}$ refers to Twin 2's score on the $\mathrm{X}$ variable and $Y_{12}$ refers to Twin 2's score on the $\mathrm{Y}$ variable.

The magic of twin studies lies in the comparison of MZ and DZ twins. The model-implied variance-covariance matrices for Figure 1 are illustrated below. 


$$
\begin{aligned}
& \begin{array}{llllllllllllllll}
A_{x 1} & C_{x 1} & E_{x 1} & A_{y 1} & C_{y 1} & E_{y 1} & A_{x 2} & C_{x 2} & E_{x 2} & A_{y 2} & C_{y 2} & E_{y 2} & X_{11} & X_{12} & Y_{11} & Y_{12}
\end{array} \\
& A_{x 1}\left(\begin{array}{rrrrrrrrrrrrrrrr}
0 & 0 & 0 & 0 & 0 & 0 & 0 & 0 & 0 & 0 & 0 & 0 & 0 & 0 & 0 & 0 \\
0 & 0 & 0 & 0 & 0 & 0 & 0 & 0 & 0 & 0 & 0 & 0 & 0 & 0 & 0 & 0
\end{array}\right) \\
& \begin{array}{lllllllllllllllll}
E_{x 1} & 0 & 0 & 0 & 0 & 0 & 0 & 0 & 0 & 0 & 0 & 0 & 0 & 0 & 0 & 0 & 0
\end{array} \\
& \begin{array}{l|llllllllllllllll}
A_{y 1} & 0 & 0 & 0 & 0 & 0 & 0 & 0 & 0 & 0 & 0 & 0 & 0 & 0 & 0 & 0 & 0
\end{array} \\
& \begin{array}{l|llllllllllllllll}
C_{y 1} & 0 & 0 & 0 & 0 & 0 & 0 & 0 & 0 & 0 & 0 & 0 & 0 & 0 & 0 & 0 & 0
\end{array} \\
& \begin{array}{l|llllllllllllllll}
E_{y 1} & 0 & 0 & 0 & 0 & 0 & 0 & 0 & 0 & 0 & 0 & 0 & 0 & 0 & 0 & 0 & 0
\end{array} \\
& \begin{array}{l|llllllllllllllll}
A_{x 2} & 0 & 0 & 0 & 0 & 0 & 0 & 0 & 0 & 0 & 0 & 0 & 0 & 0 & 0 & 0 & 0
\end{array} \\
& \mathbf{A}=\begin{array}{c|llllllllllllllll}
C_{x 2} & 0 & 0 & 0 & 0 & 0 & 0 & 0 & 0 & 0 & 0 & 0 & 0 & 0 & 0 & 0 & 0 \\
E_{x 2} & 0 & 0 & 0 & 0 & 0 & 0 & 0 & 0 & 0 & 0 & 0 & 0 & 0 & 0 & 0 & 0
\end{array} \\
& \begin{array}{l|llllllllllllllll}
A_{y 2} & 0 & 0 & 0 & 0 & 0 & 0 & 0 & 0 & 0 & 0 & 0 & 0 & 0 & 0 & 0 & 0
\end{array} \\
& \begin{array}{l|llllllllllllllll}
C_{y 2} & 0 & 0 & 0 & 0 & 0 & 0 & 0 & 0 & 0 & 0 & 0 & 0 & 0 & 0 & 0 & 0
\end{array} \\
& \begin{array}{l|llllllllllllllll}
E_{y 1} & 0 & 0 & 0 & 0 & 0 & 0 & 0 & 0 & 0 & 0 & 0 & 0 & 0 & 0 & 0 & 0
\end{array} \\
& \begin{array}{l|llllllllllllllll}
X_{11} & a_{x 1} & c_{x 1} & e_{x 1} & 0 & 0 & 0 & 0 & 0 & 0 & 0 & 0 & 0 & 0 & 0 & 0 & 0
\end{array} \\
& \begin{array}{l|llllllllllllllll}
X_{12} & 0 & 0 & 0 & 0 & 0 & 0 & 0 & 0 & 0 & 0 & 0 & 0 & 0 & 0 & 0 & 0
\end{array} \\
& Y_{11} \quad \begin{array}{cccccccccccccccc}
a_{11} & c_{11} & e_{11} & a_{y 1} & c_{y 1} & e_{y 1} & 0 & 0 & 0 & 0 & 0 & 0 & 0 & 0 & 0 & 0 \\
0 & 0 & 0 & 0 & 0 & 0 & a_{11} & c_{11} & e_{11} & a_{y 1} & c_{y 1} & e_{y 1} & 0 & 0 & 0 & 0
\end{array} \\
& Y_{12}\left(\begin{array}{llllllllllllllll}
0 & 0 & 0 & 0 & 0 & 0 & a_{11} & c_{11} & e_{11} & a_{y 1} & c_{y 1} & e_{y 1} & 0 & 0 & 0 & 0
\end{array}\right)
\end{aligned}
$$

$$
\begin{aligned}
& \begin{array}{llllllllllllllll}
A_{x 1} & C_{x 1} & E_{x 1} & A_{y 1} & C_{y 1} & E_{y 1} & A_{x 2} & C_{x 2} & E_{x 2} & A_{y 2} & C_{y 2} & E_{y 2} & X_{11} & X_{12} & Y_{11} & Y_{12}
\end{array} \\
& A_{x 1}\left(\begin{array}{rrrrrrrrrrrrrrrrr}
1 & 0 & 0 & 0 & 0 & 0 & 1 & 0 & 0 & 0 & 0 & 0 & 0 & 0 & 0 & 0 \\
0 & 1 & 0 & 0 & 0 & 0 & 0 & 1 & 0 & 0 & 0 & 0 & 0 & 0 & 0 & 0
\end{array}\right. \\
& \begin{array}{l|llllllllllllllll}
C_{x 1} & 0 & 1 & 0 & 0 & 0 & 0 & 0 & 1 & 0 & 0 & 0 & 0 & 0 & 0 & 0 & 0
\end{array} \\
& \begin{array}{l|llllllllllllllll}
E_{x 1} & 0 & 0 & 1 & 0 & 0 & 0 & 0 & 0 & 0 & 0 & 0 & 0 & 0 & 0 & 0 & 0
\end{array} \\
& \begin{array}{l|llllllllllllllll}
A_{y 1} & 0 & 0 & 0 & 1 & 0 & 0 & 0 & 0 & 0 & 1 & 0 & 0 & 0 & 0 & 0 & 0
\end{array} \\
& \begin{array}{l|llllllllllllllll}
C_{y 1} & 0 & 0 & 0 & 0 & 1 & 0 & 0 & 0 & 0 & 0 & 1 & 0 & 0 & 0 & 0 & 0
\end{array} \\
& \begin{array}{lllllllllllllllll}
E_{y 1} & 0 & 0 & 0 & 0 & 0 & 1 & 0 & 0 & 0 & 0 & 0 & 0 & 0 & 0 & 0 & 0
\end{array} \\
& \begin{array}{l|llllllllllllllll}
A_{x 2} & 1 & 0 & 0 & 0 & 0 & 0 & 1 & 0 & 0 & 0 & 0 & 0 & 0 & 0 & 0 & 0
\end{array} \\
& \mathbf{S}=\begin{array}{l|llllllllllllllll}
C_{x 2} & 0 & 1 & 0 & 0 & 0 & 0 & 0 & 1 & 0 & 0 & 0 & 0 & 0 & 0 & 0 & 0 \\
E_{x 2} & 0 & 0 & 0 & 0 & 0 & 0 & 0 & 0 & 1 & 0 & 0 & 0 & 0 & 0 & 0 & 0
\end{array} \\
& \begin{array}{r|rlllllllllllllll}
A_{x 2} & 0 & 0 & 0 & 0 & 0 & 0 & 0 & 0 & 1 & 0 & 0 & 0 & 0 & 0 & 0 & 0 \\
A_{y 2} & 0 & 0 & 0 & 1 & 0 & 0 & 0 & 0 & 0 & 1 & 0 & 0 & 0 & 0 & 0 & 0
\end{array} \\
& \begin{array}{l|llllllllllllllll}
C_{y 2} & 0 & 0 & 0 & 0 & 1 & 0 & 0 & 0 & 0 & 0 & 1 & 0 & 0 & 0 & 0 & 0
\end{array} \\
& \begin{array}{l|llllllllllllllll}
E_{y 1} & 0 & 0 & 0 & 0 & 0 & 0 & 0 & 0 & 0 & 0 & 0 & 1 & 0 & 0 & 0 & 0
\end{array} \\
& \begin{array}{l|llllllllllllllll}
X_{11} & 0 & 0 & 0 & 0 & 0 & 0 & 0 & 0 & 0 & 0 & 0 & 0 & 0 & 0 & 0 & 0
\end{array} \\
& \begin{array}{l|llllllllllllllll}
X_{12} & 0 & 0 & 0 & 0 & 0 & 0 & 0 & 0 & 0 & 0 & 0 & 0 & 0 & 0 & 0 & 0
\end{array} \\
& \left.\begin{array}{l|llllllllllllllll}
Y_{11} & 0 & 0 & 0 & 0 & 0 & 0 & 0 & 0 & 0 & 0 & 0 & 0 & 0 & 0 & 0 & 0 \\
Y_{12} & 0 & 0 & 0 & 0 & 0 & 0 & 0 & 0 & 0 & 0 & 0 & 0 & 0 & 0 & 0 & 0
\end{array}\right)
\end{aligned}
$$

$\begin{array}{llllllllllllllll}A_{x 1} & C_{x 1} & E_{x 1} & A_{y 1} & C_{y 1} & E_{y 1} & A_{x 2} & C_{x 2} & E_{x 2} & A_{y 2} & C_{y 2} & E_{y 2} & X_{11} & X_{12} & Y_{11} & Y_{12}\end{array}$ $\mathbf{F}=\begin{aligned} & X_{11} \\ & X_{11} \\ & Y_{11} \\ & Y_{11}\end{aligned}\left(\begin{array}{llllllllllllllll}0 & 0 & 0 & 0 & 0 & 0 & 0 & 0 & 0 & 0 & 0 & 0 & 1 & 0 & 0 & 0 \\ 0 & 0 & 0 & 0 & 0 & 0 & 0 & 0 & 0 & 0 & 0 & 0 & 0 & 1 & 0 & 0 \\ 0 & 0 & 0 & 0 & 0 & 0 & 0 & 0 & 0 & 0 & 0 & 0 & 0 & 0 & 0 & 1\end{array}\right)$

$$
\boldsymbol{\Sigma}_{\text {observed }}=\begin{gathered}
X_{11} \\
X_{11} \\
X_{12} \\
Y_{11} \\
Y_{12}
\end{gathered}\left(\begin{array}{ccccc}
\operatorname{Var}\left(X_{11}\right) & X_{12} & Y_{11} & Y_{12} \\
\operatorname{Cov}\left(X_{11}, X_{12}\right) & \operatorname{Var}\left(X_{12}\right) & & \\
\operatorname{Cov}\left(X_{11}, Y_{11}\right) & \operatorname{Cov}\left(X_{12}, Y_{11}\right) & \operatorname{Var}\left(Y_{11}\right) & \\
\operatorname{Cov}\left(X_{11}, Y_{12}\right) & \operatorname{Cov}\left(X_{12}, Y_{12}\right. & \operatorname{Cov}\left(Y_{11}, Y_{12}\right) & \operatorname{Var}\left(Y_{12}\right)
\end{array}\right)
$$




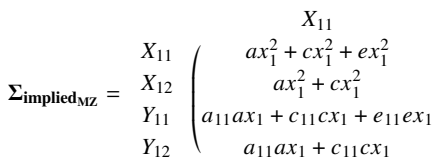

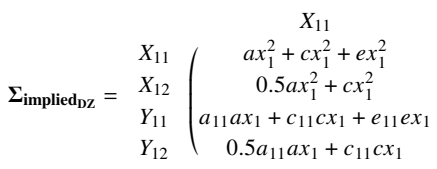

$$
\begin{aligned}
& \begin{array}{c}
X_{12} \\
a x_{1}^{2}+c x_{1}^{2} \\
a x_{1}^{2}+c x_{1}^{2}+e x_{1}^{2} \\
a_{11} a x_{1}+c_{11} c x_{1} \\
a_{11} a x_{1}+c_{11} c x_{1}+e e_{11} e x_{1} \\
X_{12} \\
0.5 a x_{1}^{2}+c x_{1}^{2} \\
a x_{1}^{2}+c x_{1}^{2}+e x_{1}^{2} \\
0.5 a_{11} a x_{1}+c_{11} c x_{1} \\
a_{11} a x_{1}+c_{11} c x_{1}+e_{11} e x_{1}
\end{array} \\
& \begin{array}{c}
Y_{11} \\
a_{11} a x_{1}+c_{11} c x_{1}+e_{11} e x_{1} \\
a_{11} a x_{1}+c_{11} c x_{1} \\
a_{11}^{2}+a y_{1}^{2}+c_{11}^{2}+c y_{1}^{2}+e_{11}^{2}+e y_{1}^{2} \\
a_{11}^{2}+a y_{1}^{2}+c_{11}^{2}+c y_{1}^{2} \\
Y_{11} \\
a_{11} a x_{1}+c_{11} c x_{1}+e_{11} e x_{1} \\
0.5 a_{11} a x_{1}+c_{11} c x_{1} \\
a_{11}^{2}+a y_{1}^{2}+c_{11}^{2}+c y_{1}^{2}+e_{11}^{2}+e y_{1}^{2} \\
0.5 a_{11}^{2}+0.5 a y_{1}^{2}+c_{11}^{2}+c y_{1}^{2}
\end{array} \\
& \left.\begin{array}{c}
Y_{12} \\
a_{11} a x_{1}+c_{11} c x_{1} \\
a_{11} a x_{1}+c_{11} c x_{1}+e_{11} e x_{1} \\
a_{11}^{2}+a y_{1}^{2}+c_{11}^{2}+c y_{1}^{2} \\
a_{11}^{2}+a y_{1}^{2}+c_{11}^{2}+c y_{1}^{2}+e_{11}^{2}+e y_{1}^{2}
\end{array}\right)
\end{aligned}
$$

For a full exposition of the various components of this matrix we refer to Neale and Cardon (2013). There are a couple of points worth noting of relevance for this paper, however.

First of all, the variance of $X_{11}$ and $X_{12}$ are the same i.e. $a x_{1}^{2}+c x_{1}^{2}+e x_{1}^{2}$ and its sum simply corresponds to the phenotypic variance i.e. $\operatorname{Var}\left(X_{11}\right)$. In a sense this thus would be the same result if we had simply run a univariate ACE model. We also note that the covariance between the two $\mathrm{X}$ variables is what makes the estimation of heritability possible, since this varies for $\mathrm{MZ}$ and DZ twin pairs i.e. $a x_{1}^{2}+c x_{1}^{2}$ vs. $0.5 a x_{1}^{2}+c x_{1}^{2}$ respectively.

The most important part is of course the fact that the model introduces two phenotypes, i.e. $\mathrm{X}$ and $\mathrm{Y}$. The variance for $\mathrm{Y}$ is also constrained to be equal for the two traits and is now both a function of the cross paths $a_{11}^{2}+a y_{1}^{2}+c_{11}^{2}$ but also the variance components for $\mathrm{Y}\left(c y_{1}^{2}+e_{11}^{2}+e y_{1}^{2}\right)$. The full variance for $\mathrm{Y}$ is $a_{11}^{2}+a y_{1}^{2}+c_{11}^{2}+c y_{1}^{2}+e_{11}^{2}+e y_{1}^{2}$. Speaking in terms of a regression framework, the cross paths simply correspond to a regression of $\mathrm{X}$ on $\mathrm{Y}$ (where the effect is then separated into A, C, and E components) and the A, C, and E components for $\mathrm{Y}$ simply correspond to the residual variance after the effect of $\mathrm{X}$ on $\mathrm{Y}$ is taken into account.

What makes the model interesting from a causal point of view is the ability to "partial out" any effect of (additive) genetic confounding and confounding by family upbringing on the effect of education on political engagement. Much of this information is contained in the so-called "cross-twin covariance," which differs by zygosity. These come in two variants: The within-twin cross-trait covariance $a_{11} a x_{1}+c_{11} c x_{1}+e_{11} e x_{1}$ corresponds to the phenotypic correlation between the traits and would thus be what we would be interested in if we were simply calculating a simple cross-sectional estimate of the covariance between the traits. If the cross-twin cross-trait covariances $\left(0.5 a_{11} a x_{1}+c_{11}\right.$ for DZ twins and $a_{11} a x_{1}+c_{11}$ for MZ twins) are smaller than this estimate, it suggests familial confounding is at play. If the MZ within-twin cross-trait covariance is smaller than for DZ twins, this suggests that (at least part of) this confounding is caused by genetic confounding. 